\title{
Hyperoxia increases arterial oxygen pressure during exercise in type 2 diabetes patients: a feasibility study
}

\author{
Robert Rozenberg ${ }^{1}$, Robert T. Mankowski ${ }^{*}$, Luc J. C. van Loon², Janneke G. Langendonk ${ }^{3}$ Eric J. G. Sijbrands ${ }^{3}$,
} Anton H. van den Meiracker ${ }^{3}$, Henk J. Stam ${ }^{1}$ and Stephan F. E. Praet ${ }^{1}$

\begin{abstract}
Objective: The study investigated the feasibility and potential outcome measures during acute hyperoxia in type 2 diabetes patients (DM2).

Methods: Eleven DM2 patients (7 men and 4 women) were included in the study. The patients cycled (30 min at $20 \% \mathrm{~W}_{\max }$ ) whilst breathing three different supplemental oxygen flows $\left(\mathrm{SOF}, 5,10,15 \mathrm{~L} \mathrm{~min}^{-1}\right.$ ). During hyperoxic exercise, arterial blood gases and intra-arterial blood pressure measurements were obtained.

Results: Arterial $\mathrm{pO}_{2}$ levels increased significantly (ANOVA, $\left.p<0.05\right)$ with SOF: $13.9 \pm 1.2\left(0 \mathrm{~L} \mathrm{~min}^{-1}\right) ; 18.5 \pm 1.5$ $\left(5 \mathrm{~L} \mathrm{~min}^{-1}\right) ; 21.7 \pm 1.7\left(10 \mathrm{~L} \mathrm{~min}^{-1}\right) ; 24.0 \pm 2.3\left(15 \mathrm{~L} \mathrm{~min}^{-1}\right)$. Heart rate $(\mathrm{HR})$ and $\mathrm{pH}$ increased significantly after terminating administration of hyperoxic air.
\end{abstract}

Conclusions: An SOF of $15 \mathrm{~L} \mathrm{~min}^{-1}$ appears to be more effective than 5 or $10 \mathrm{~L} \mathrm{~min}^{-1}$. Moreover, HR, blood pressure, blood lactate and $\mathrm{pH}$ are not recommended as primary outcome measures.

Keywords: Diabetes type 2, Hyperoxia, Exercise, Oxygen, Dose

\section{Background}

Breathing a hyperoxic gas mixture has been shown to acutely enhance power output (W) by $8-13 \%$ [1-6], increase oxygen uptake $\left(\dot{V} \mathrm{O}_{2}\right)$ by $10-14 \%[2,3,6-10]$, decrease blood lactate level [11] and lower perceived exertion [7] during aerobic type of exercise. Both healthy subjects and COPD patients show improved exercise performance with hyperoxia [12-14]. These findings suggest that certain other clinical populations with impaired cardiovascular and/or pulmonary fitness levels might benefit from exercise under hyperoxic conditions as well. Patients with type 2 diabetes (DM2) might be good candidates for hyperoxic exercise training as previous research indicated that DM2 patients frequently have a reduced diffusion capacity of the lungs (8-25\%),

\footnotetext{
*Correspondence: r.mankowski@ufl.edu

1 Subdivision MOVEFIT-Sports Medicine, Department of Rehabilitation Medicine, Erasmus University Medical Center, Wytemaweg 80, 3000 CA Rotterdam, The Netherlands

Full list of author information is available at the end of the article
}

inversely related to blood glucose levels as well as duration and severity of DM2 [15-17]. Pathophysiological mechanisms explaining the impaired pulmonary function may be micro-angiopathy, chronic inflammation and autonomic neuropathy $[16,18]$ resulting in a diminished alveolar micro-vascular reserve [15, 17, 19-21]. Impaired alveolar gas exchange in DM2 patients has been shown to correlate with a lower $\dot{V} \mathrm{O}_{2}$ and workload capacity during aerobic type of exercise [22].

Although beneficial effects of exercise under hyperoxic conditions have been reported for different types of chronic disease populations $[1,4,8,23-26]$, experimental data on an effective dose of hyperoxic air during exercise in DM2 patients are still lacking. Despite the ongoing debate on oxygen transport and consumption [50], increased oxygen availability in arterial blood may improve intracellular transport and uptake of active muscle tissue, and subsequently improve exercise performance. In accordance, the aim of the present feasibility study was to establish an effective dose of supplemental 
oxygen in DM2 population as a basis to guide and optimise future hyperoxic exercise training protocols.

\section{Methods}

\section{Subjects}

Eleven patients diagnosed with DM2 for at least 2 years and not taking anti-hypertensive medication were screened and included at the outpatient clinic at Erasmus University Medical Center in Rotterdam, the Netherlands. The characteristics of the eligible patients are presented in Table 1. Out of 22 screened patients, a total of six patients were not willing to participate in the hyperoxic exercise intervention following the maximal exercise test. Four patients were excluded from the hyperoxic experiment because it was not possible to introduce an intra-arterial catheter in the radial artery. One patient was excluded from our study because of abnormally high lactate levels during exercise and was diagnosed with mitochondrial encephalomyopathy, lactic acidosis, and stroke-like episodes (MELAS) syndrome afterwards. Baseline characteristics of excluded patients were not different from the experimental group. Included subjects gave their informed consent to participate in the study, approved by the medical ethical committee of the Erasmus University Medical Center in Rotterdam (ISRCTN number: NTR2299).

\section{Procedures}

Prior to the hyperoxic exercise session all subjects performed a maximal exercise test on a cycle ergometer (Jaeger ER800) using an incremental workload $(1.85 \mathrm{~W} / 6 \mathrm{~s}$ for men, $1.2 \mathrm{~W} / 6 \mathrm{~s}$ for women). The oxygen uptake $\left(\dot{V} \mathrm{O}_{2}\right)$ (Oxycon Pro, Viasys, Houten, Netherlands) and heart rate (HR) (Polar wear-link, Finland) were measured continuously. A second visit was scheduled within 1-3 weeks following a maximal exercise test. During the second visit

Table 1 Subject characteristics

\begin{tabular}{ll}
\hline $\mathbf{n}=\mathbf{1 1})$ & Mean \pm SD \\
\hline Sex (M:F) & $7: 4$ \\
Age (years) & $56.3 \pm 6.3$ \\
T2D duration (years) & $10.5 \pm 6.6$ \\
Weight (kg) & $87.7 \pm 16.5$ \\
Length (cm) & $171.1 \pm 11.0$ \\
BMl (kg/m $\left.{ }^{2}\right)$ & $30.1 \pm 6.1$ \\
Abdominal circumference (cm) & $100 \pm 13$ \\
Fat percentage $(\%)$ & $33.9 \pm 9.1$ \\
Fasting glucose (mmol/L) & $11.3 \pm 3.0$ \\
HbA1c (\%) & $8.3 \pm 1.3$ \\
\hline
\end{tabular}

No significant differences $(p<0.05)$

a Based on skinfold measurements (Durnin and Womersley 1969) subjects performed a hyperoxic exercise session. The bout consisted of 25 min of submaximal cycling at $20 \%$ of the maximal workload capacity $\left(W_{\max }\right)$. The workload was chosen to ensure that the subjects reach steady state, based on the assumption that the anaerobic threshold is at least $40 \% W_{\max }$ in DM2 patients. After calibration patients underwent the Allen's test, and subsequently beat-to-beat blood pressure was obtained through a percutaneous intra-articular catheter in the radial artery of the non-dominant hand [51]. Data were registered in a computer and analysed using specialised software (Beat scope, Finapres Medical Systems, Amsterdam, the Netherlands). It was performed to minimise the risk of ischaemia of the hand. The exercise protocol consisted of 6 phases: 5 min of rest without supplemental oxygen flow (SOF), $10 \mathrm{~min}$ without SOF, $5 \mathrm{~min}$ with $5 \mathrm{~L} \mathrm{~min}^{-1} \mathrm{SOF}$, $5 \mathrm{~min}$ with $10 \mathrm{~L} \mathrm{~min}^{-1} \mathrm{SOF}, 5 \mathrm{~min}$ with $15 \mathrm{~L} \mathrm{~min}^{-1} \mathrm{SOF}$, 5 min without SOF (Fig. 1). A stage duration of $5 \mathrm{~min}$ was chosen to reach steady state during, at least, the last 2 min of each stage [27, 28]. The last stage was added to assess the effect of cessation of SOF.

The SOF was administered directly into a face mask (without a reservoir bag, Teleflex Inc. Hudson RCI adult Multi-Vent air entrainment mask), allowing the inhalation of room air to meet the subjects' ventilatory demands. In our study, we chose to dose oxygen as a fixed flow quantity, instead of a fixed inspirational fraction with a maximum of $15 \mathrm{~L} \mathrm{~min}^{-1}$. This design was chosen to match the possibilities of the standard facilities for supplemental oxygen available in most primary and secondary healthcare settings. During the last min of each phase arterial blood gas and the rate of perceived exertion (Borg score) [29] were obtained.

\section{Statistical analysis}

An independent sample $T$ test was used to analyse the baseline characteristics and maximal exercise test. We used a single-factor ANOVA with repeated measures to compare the means of the given variables during different hyperoxic exercise phases. Differences with a $p$ value $<0.05$ were considered significant. The Bonferroni adjustment was applied. Data were presented as mean \pm SD.

\section{Results Participants \\ The characteristics of the included participants are pre- sented in Table 1.}

\section{Maximal exercise test}

The average maximal oxygen uptake $\left(V \mathrm{O}_{2 \max }\right)$ of the subjects was $1.83 \pm 0.59 \mathrm{~L} \mathrm{~min}^{-1}$. The mean $V \mathrm{O}_{2 \max }$ was on average $\sim 24 \%(p<0.05)$ below the average of a healthy population of the same age, weight, length and sex based 


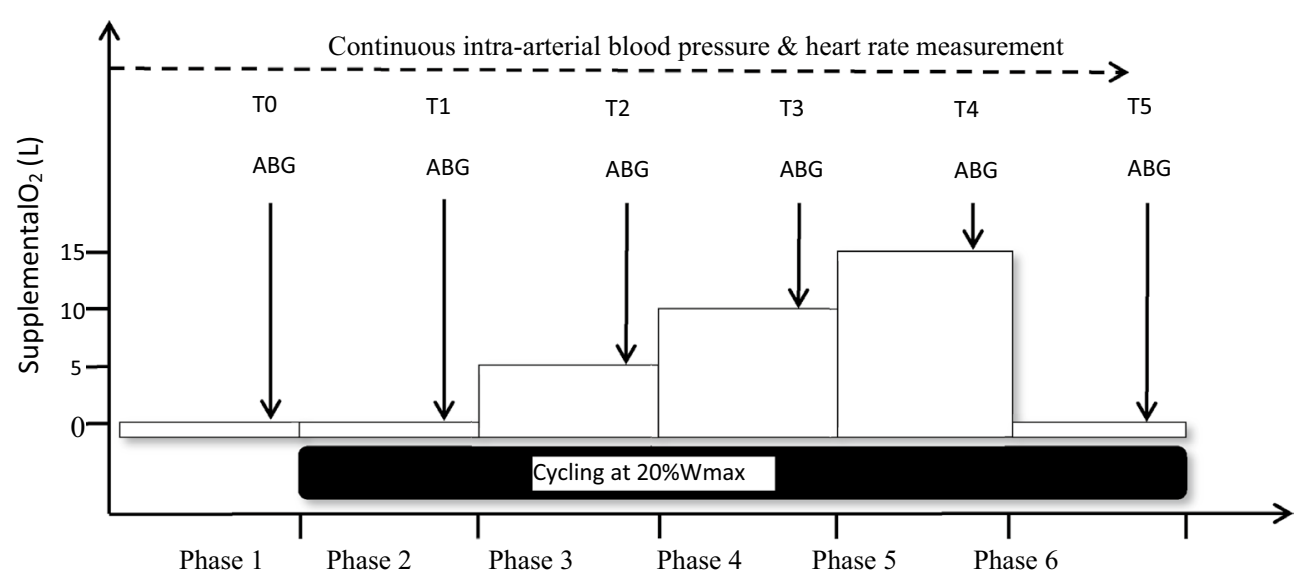

Fig. 1 Hyperoxic exercise protocol. ABG arterial blood gas, RPE rate of perceived exertion (Borg score)

on the regression equations by Fairbarn et al. [30]. Maximal HR was not significantly different form the predicted values according to the Tanaka regression equation [31]. The results of the maximal exercise test are presented in Table 2.

\section{Hyperoxic exercise: blood gas analysis}

All included subjects were able to complete $25 \mathrm{~min}$ of submaximal hyperoxic exercise. Arterial $\mathrm{pO}_{2}$ levels (Fig. 2a) did not change immediately after starting the exercise (T1-2). The arterial $\mathrm{pO}_{2}$ increased significantly with increased SOF (T2-T5) in a dose-dependent manner and returned to baseline after cessation of the SOF administration (T5-T6). The arterial $\mathrm{pCO}_{2}$ (Fig. 2b) did not change significantly in response to exercise under different SOF.

There was a decreasing trend of the $\mathrm{pH}$ (Fig. 2c) at the onset of the exercise bout (T1-T2), while $\mathrm{pH}$ increased significantly ( $p$ value) during the last step when the supplemental oxygen flow administration was stopped (T5-T6).

\section{Hyperoxic exercise: $\mathrm{HR}$, blood pressure and rate of perceived exertion}

The HR (Fig. 3a) increased significantly after the onset of the exercise bout (T1-T2), and remained unchanged during the SOF phases (T2-T5) and increased after stopping the SOF (T5-T6). After an initial increase of systolic and diastolic blood pressure after starting the exercise (T1-2), systolic, diastolic and mean arterial blood pressure (Fig. 3b-d) did not change during the SOF. Furthermore, the rate pressure product (Fig. 3e) showed a significant increase after stopping the SOF (T5-T6). The rate of perceived exertion (Fig. 3f) increased with the start of exercise (T1-2) and did not increase significantly during exercise (T2-T6).

\section{Discussion}

We tested the feasibility of hyperoxic exercise and doseresponse in type 2 diabetes patients. The main finding of this feasibility study was that exercise under SOF $15 \mathrm{~L} \mathrm{~min}^{-1}$ increased $\mathrm{pO}_{2}$ more effectively than lower doses (5 and $10 \mathrm{~L} \mathrm{~min}^{-1}$ ) in DM2 patients (Table 3).

\section{Technical feasibility}

From a technical perspective, our results demonstrate that supplemental oxygen, applied with a standard open facemask (5-15 $\left.\mathrm{L} \mathrm{min}{ }^{-1}\right)$, results in significant increases in arterial $\mathrm{pO}_{2}$ levels during exercise. Higher $\mathrm{pO}_{2}$ at increased SOF (i.e. 5, 10 and $15 \mathrm{~L} \mathrm{~min}^{-1}$ ) suggests a dose-dependent effect. The $\mathrm{pO}_{2}$ levels obtained from the radial artery during hyperoxic exercise in the present study $(24.0 \pm 2.3 \mathrm{kPa})$ were comparable with the arterial $\mathrm{pO}_{2}$ levels measured by Plet et al. in healthy subjects. Administration of $55 \%$ of oxygen improved maximal oxygen uptake by $12 \%$ during cycleergometry in comparison with normoxic exercise [9]. Other studies investigating the influence of hyperoxia during exercise found slightly higher $\mathrm{pO}_{2}$ levels of approximately $40 \mathrm{kPa}$ obtained from the femoral artery with an inspired oxygen fraction of $60 \%$ [32-34]. Taken together, our data show that supplemental oxygen applied during submaximal exercise via a standard open face mask increases arterial $\mathrm{pO}_{2}$ levels. Additional oxygen availability could compensate for the diminished diffusion capacity, endothelial function and low aerobic capacity seen in most DM2 patients $[15,17$, 19-21]. The latter suggests that a hyperoxic training study in DM2 patients could be a potential solution in a medical fitness centre, since no special equipment is needed other than an open facemask and standard gas cylinders with $\mathrm{O}_{2}$. However, before investigating training effects under hyperoxic conditions, this warrants further controlled trials on cardiovascular and pulmonary function in DM2 patients. 
Table 2 Maximal exercise test

\begin{tabular}{|c|c|c|c|c|c|}
\hline & Maximal & Predicted & $\%$ Predicted & AT & Ratio AT/max \\
\hline Load (W) & $145.5 \pm 61.9$ & $182.1 \pm 74.3^{\mathrm{a}}$ & $84 \pm 24^{*}$ & $85.1 \pm 38.5$ & $0.58 \pm 0.12^{*}$ \\
\hline Load/weight (W/kg) & $1.70 \pm 0.71$ & $2.52 \pm 0.82$ & $69 \pm 23^{*}$ & $0.99 \pm 0.41$ & $0.58 \pm 0.12^{*}$ \\
\hline$\dot{\mathrm{V}} \mathrm{O}_{2}(\mathrm{ml} / \mathrm{min})$ & $1830 \pm 593$ & $2499 \pm 773^{\mathrm{a}}$ & $76 \pm 21^{*}$ & $1334 \pm 354$ & $0.75 \pm 0.13^{*}$ \\
\hline$\dot{\mathrm{V}} \mathrm{O}_{2}(\mathrm{ml} / \mathrm{min} \mathrm{kg})$ & $21.4 \pm 7.0$ & $28.9 \pm 8.8$ & $76 \pm 24^{*}$ & $15.5 \pm 4.0$ & $0.75 \pm 0.13^{*}$ \\
\hline $\mathrm{HR}(\mathrm{bpm})$ & $155 \pm 18$ & $169 \pm 5^{b}$ & $92 \pm 10$ & $128 \pm 17$ & $0.83 \pm 0.08^{*}$ \\
\hline RER & $1.09 \pm 0.09$ & & & $0.92 \pm 0.07$ & $0.85 \pm 0.07^{*}$ \\
\hline Systolic blood pressure $(\mathrm{mmHg})$ & $180 \pm 30$ & & & & \\
\hline Diastolic blood pressure $(\mathrm{mmHg})$ & $79 \pm 12$ & & & & \\
\hline RPE (Borg & $15.8 \pm 2.8$ & & & & \\
\hline
\end{tabular}

AT anaerobic threshold using V-slope method

a Using the Fairbarn and Wasserman equations (Fairbarn et al. [30])

b Using the Tanaka equation (Tanaka et al. [31])

* Significant difference $(p<0.05)$
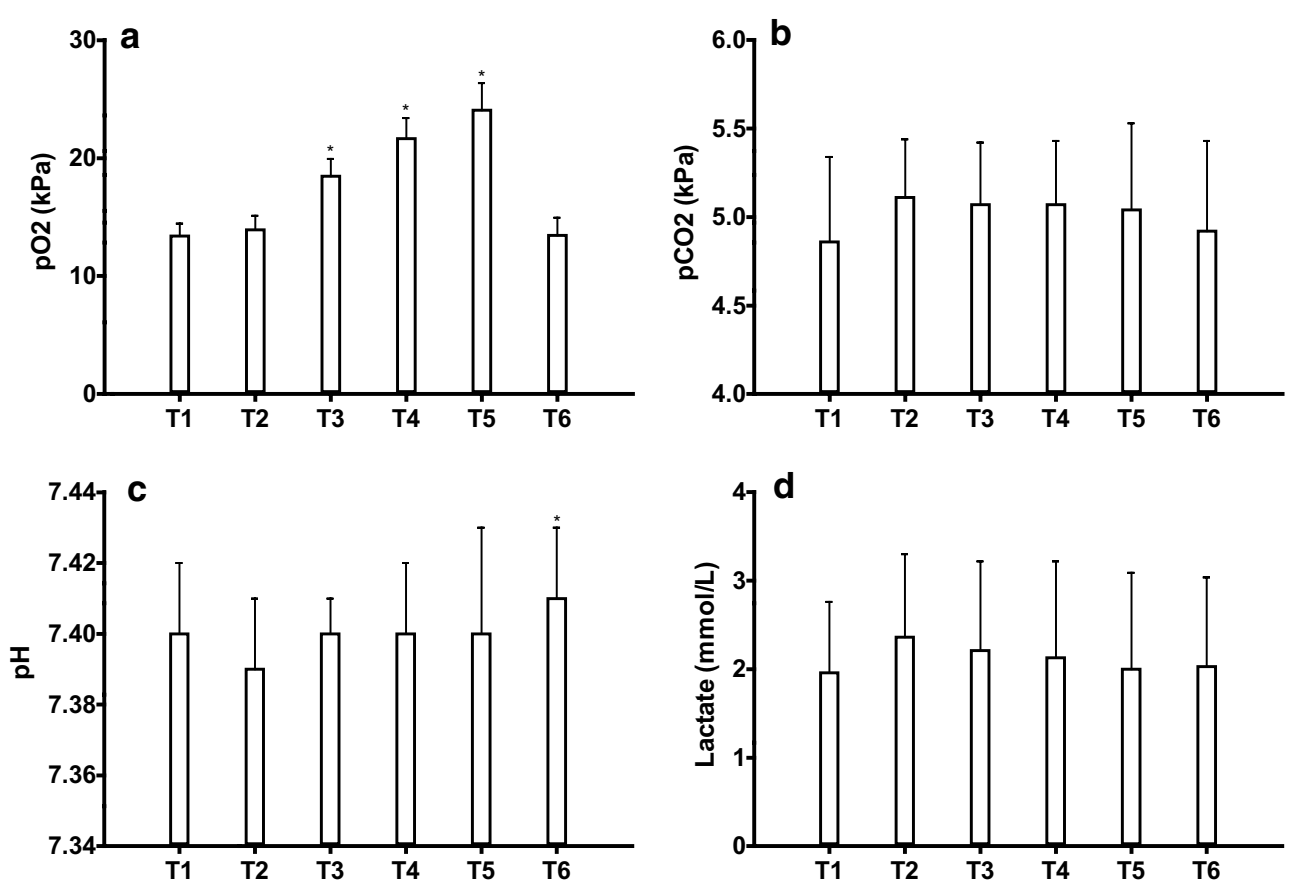

Fig. 2 Blood gas analysis a $\mathrm{pO}_{2}$ levels during hyperoxic exercise. ${ }^{*} T 3-5$ are significantly different from $T 1, T 2$ and $T 6$, and each other $(p<0.05)$. b pCO2 levels during hyperoxic exercise. No significant changes $(p<0.05)$. $\mathbf{c}$ pH levels during hyperoxic exercise. ${ }^{*} \mathrm{~T} 6$ is significantly higher than T2 and T3 $(p<0.05)$. d Lactate levels during hyperoxic exercise. No significant changes $(p<0.05)$

The results will improve our understanding on whether additional oxygen during exercise may improve oxidative metabolism in populations such as DM2 with deficient cardiovascular and respiratory function.

\section{Patient recruitment and study population}

Despite the invasive nature of our study and the fact that use of antihypertensive medication was an exclusion criterion for the present study, the majority $(=76 \%)$ of the eligible DM2 patients that were approached in our outpatient clinic were willing to participate in our feasibility study. Although, a training study requires a more long-term commitment, the willingness to participate in our feasibility study indicates that it might be possible to recruit a sufficient and representative proportion of subjects for a randomized 

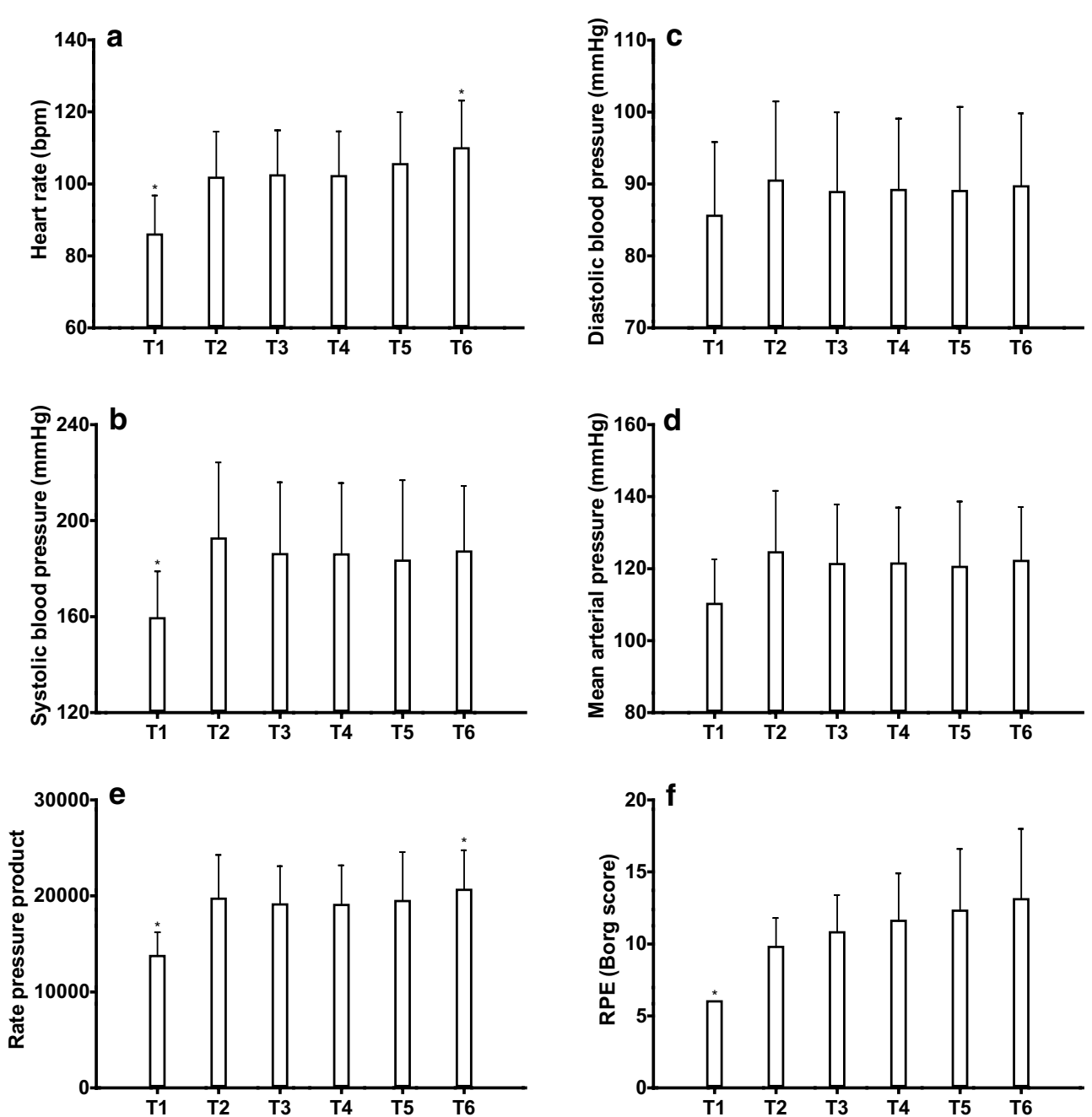

Fig. 3 Cardiovascular response and rate of perceived exertion a HR during hyperoxic exercise. ${ }^{*} \mathrm{~T} 1$ is significantly lower than T2-6. T6 is significantly higher than T1, T3, and T4 $(p<0.05)$. b Systolic blood pressure during hyperoxic exercise. ${ }^{*} T 1$ is significantly lower than T2, T3 and T6 ( $\left.p<0.05\right)$. c Diastolic blood pressure during hyperoxic exercise. No significant changes $(p<0.05)$. d Mean arterial blood pressure during hyperoxic exercise. No significant changes $(p<0.05)$. e Rate pressure product during hyperoxic exercise. *T1 is significantly lower than T2-6. T6 is significantly higher than T1 and T3 $(p<0.05)$. f Rate of perceived exertion (Borg score) during hyperoxic exercise. *T1 is significantly lower T2-T6 ( $p<0.05)$

clinical trial on the medium-term effects of hyperoxic exercise training.

In accordance with previous studies [35-38], the mean $\mathrm{VO}_{2 \max }$ of the investigated patient sample is well below the average of the healthy population, even when corrected for a high BMI. High HbA1c and fasting glucose levels showed that our overweight subjects had poorly regulated DM2. As such, the present study population may not be representative for the general wellcontrolled DM2 population. Long-term adherence has been reported to vary substantially $(10-80 \%)$ in conventional exercise programs for DM2 patients [39-44]. However, effects of hyperoxic exercise training in other patient populations, with a reduced alveolar and capillary diffusion capacity [12-14], showed the anticipated increase in exercise capacity. Less perceived exercise intensity and improvement of exercise performance will also motivate overweight and with poorly regulated DM2 patients to adhere to hyperoxic exercise training.

\section{Potential outcome measures}

In contrast with previous hyperoxic exercise studies $[8$, 9, 33, 45-47], we observed no change in HR, blood pressure or rate of perceived exertion during exercise while increasing the supplemental oxygen flow during exercise. However, after stopping administration of SOF we observed a significant increase in HR and rate pressure product $[\mathrm{HR} *$ systolic blood pressure (SBP)]. The 
Table 3 Hyperoxic exercise session

\begin{tabular}{lcccccc}
\hline & T1 & T2 & T3 & T4 & T5 & T6 \\
\hline pO2 $(\mathrm{kPa})$ & $13.4 \pm 1.1$ & $13.9 \pm 1.2$ & $18.5 \pm 1.5^{\mathrm{a}}$ & $21.7 \pm 1,7^{\mathrm{a}}$ & $24.0 \pm 2.3^{\mathrm{a}}$ & $13.5 \pm 1.5$ \\
Oxygen content (mmol/L) & $8.3 \pm 1.0$ & $8.3 \pm 0.9$ & $8.3 \pm 1.0$ & $8.6 \pm 1.2$ & $8.4 \pm 1.0$ & $8.2 \pm 1.1$ \\
pCO2 $(\mathrm{kPa})$ & $4.9 \pm 0.5$ & $5.1 \pm 0.3$ & $5.1 \pm 0.4$ & $5.1 \pm 0.4$ & $5.0 \pm 0.5$ & $4.9 \pm 0.5$ \\
$\mathrm{pH}$ & $7.40 \pm 0.02$ & $7.39 \pm 0.02$ & $7.40 \pm 0.01$ & $7.40 \pm 0.02$ & $7.40 \pm 0.03$ & $7.41 \pm 0.02^{\mathrm{b}}$ \\
Lactate $(\mathrm{mmol} / \mathrm{L})$ & $1.96 \pm 0.80$ & $2.36 \pm 0.94$ & $2.21 \pm 1.01$ & $2.13 \pm 1.09$ & $2.00 \pm 1.09$ & $2.03 \pm 1.10$ \\
Heart rate $(\mathrm{bpm})$ & $86 \pm 11^{\mathrm{c}}$ & $102 \pm 13$ & $102 \pm 13$ & $102 \pm 12$ & $106 \pm 12$ & $110 \pm 13^{\mathrm{c}}$ \\
Systolic blood pressure $(\mathrm{mmHg})$ & $159.4 \pm 19.5^{\mathrm{d}}$ & $192.6 \pm 31.7$ & $186.1 \pm 30.0$ & $186.0 \pm 29.7$ & $183.3 \pm 33.5$ & $187.1 \pm 27.3$ \\
Diastolic blood pressure $(\mathrm{mmHg})$ & $85.6 \pm 10.2$ & $90.5 \pm 11.0$ & $88.9 \pm 11.1$ & $89.1 \pm 9.9$ & $89.0 \pm 11.7$ & $89.7 \pm 10.1$ \\
Rate pressure product & $13,626 \pm 2483^{\mathrm{e}}$ & $19,722 \pm 4569$ & $19,106 \pm 4000$ & $19,062 \pm 4115$ & $19,471 \pm 5112$ & $20,627 \pm 4137^{\mathrm{e}}$ \\
Mean arterial pressure $(\mathrm{mmHg})$ & $110.2 \pm 12.4$ & $124.5 \pm 17.1$ & $121.3 \pm 16.6$ & $121.4 \pm 15.6$ & $120.5 \pm 18.2$ & $122.2 \pm 15.0$ \\
Rate of perceived exertion $(/ 20)$ & $6.0 \pm 0.0^{\mathrm{f}}$ & $9.8 \pm 2.0$ & $10.8 \pm 2.6$ & $11.6 \pm 3.3$ & $12.3 \pm 4.3$ & $13.1 \pm 4.9$ \\
\hline
\end{tabular}

a T3-5 are significantly different from T1, T2 and T6, and each other $(p<0.05)$

b $\mathrm{T} 6$ is significantly higher than $\mathrm{T} 2$ and $\mathrm{T} 3(\mathrm{p}<0.05)$

c T1 is significantly lower than T2-6. T6 is significantly higher than T1, T3, and T4 $(p<0.05)$

d $\mathrm{T} 1$ is significantly lower than T2, T3 and T6 $(p<0.05)$

e T1 is significantly lower than T2-6. T6 is significantly higher than T1 and T3 $(p<0.05)$

${ }^{f} \mathrm{~T} 1$ is significantly lower T2-T6 ( $\left.p<0.05\right)$

cardiovascular response during phase 6 indicates that hyperoxia lowers the cardiovascular burden during submaximal steady-state exercise in patients with DM2. A number of physiological mechanisms might explain why, in comparison with previous hyperoxic exercise studies, SOF did not lower HR and systemic blood pressure during phases 3-5 in our experimental setup. First, it is possible that even at an exercise intensity of $20 \% \dot{V} \mathrm{O}_{2} \max$ max, our patients were not completely in a steady-state condition during phases $3-5$. Second, in comparison with previous hyperoxic exercise studies, the absolute exercise intensity may have been too low to cause a significant drop in HR, blood pressure or the rate of perceived exertion (Borg score). Third, the arterial wall stiffening in combination with the diabetes-related endothelial dysfunction may have impaired a normal vascular response to hyperoxia $[48,49]$.

\section{Limitations of the study}

Unfortunately, for medical ethical reasons (invasive study) it was difficult to add a healthy control group or different oxygen conditions. Because of this limitation, we can only speculate about the physiological reason for this abnormal response to hyperoxic exercise. Arterial blood gas collection (arterial blood withdrawal) was vastly limited because of impaired structure of arterial walls in the DM2 patients. These invasive methods may be replaced by non-invasive study measures in the future studies such as bio-impedance cardiography and nearinfrared spectroscopy. Nevertheless, the present feasibility study suggests that $\mathrm{HR}$, blood pressure and rate of perceived exertion may not be suitable primary outcome measures for a hyperoxic training study in unfit DM2 patients. Instead, direct assessment of the $\mathrm{VO}_{2 \max }$ should be considered in a hyperoxic training study to monitor and document change in exercise performance.

\section{Conclusions}

Based on arterial $\mathrm{pO}_{2}$ measurements, a supplemental oxygen flow of $15 \mathrm{~L} \mathrm{~min}^{-1}$ appears sufficient to compensate for impaired alveolar and capillary oxygen transport and/or consumption in DM2 patients. Based on this feasibility study, we propose to first investigate acute effects of various inspiratory oxygen fractions on the cardio-respiratory system and speed of oxygen uptake kinetics. This will improve our understanding on potential exercise performance enhancement benefits of supplementary oxygen. This would warrant future studies to investigate the medium- and long-term benefits of hyperoxic exercise training in patients with DM2.

\section{Authors' contributions}

RR and SP designed the study protocol, obtained an approval from the medical ethical committee, performed the experiments and took significant part in writing this manuscript. RM assisted during the experiments and significantly contributed in writing the manuscript. JL, ES and AM advised on the contents of the protocol and contributed inclusion of type 2 diabetes patients. HS and $\mathrm{LL}$ advised on the contents of the protocol and chosen methods and contributed significantly by revising a manuscript. All authors read and approved the final manuscript.

\section{Author details}

1 Subdivision MOVEFIT-Sports Medicine, Department of Rehabilitation Medicine, Erasmus University Medical Center, Wytemaweg 80, 3000 CA Rotterdam, The Netherlands. ${ }^{2}$ Department of Human Movement Sciences, NUTRIM School for Nutrition, Toxicology and Metabolism, Maastricht University 
Medical Centre, Universiteitssingel 50, 6229 ER Maastricht, The Netherlands. ${ }^{3}$ Section of Pharmacology, Vascular and Metabolic Diseases, Department of Internal Medicine, Erasmus University Medical Center, 's-Gravendijkwal 230, 3015 CE Rotterdam, The Netherlands.

\section{Acknowledgements}

This study was supported by the Dutch Research Foundation 2008.11.007. The authors would like to thank Ashraf Fagirzada and Mery Arevalo de Weever for their assistance with patient recruitment and experimental procedures.

\section{Competing interests}

The authors declare that they have no competing interests.

Received: 18 June 2015 Accepted: 29 December 2015

Published online: 08 January 2016

\section{References}

1. Morris DM, Kearney JT, Burke ER. The effects of breathing supplemental oxygen during altitude training on cycling performance. J Sci Med Sport. 2000:3:165-75.

2. Peltonen JE, Ritola JJ, Ahotupa, et al. Oxygen uptake response during maximal cycling in hyperoxia, normoxia and hypoxia. Aviat Space Environ Med. 2001;72:904-11.

3. Peltonen JE, Tikkanen HO, Rusko HK. Cardiorespiratory responses to exercise in acute hypoxia, hyperoxia and normoxia. Eur J Appl Physiol. 2001;85:82-8

4. Ploutz-Snyder LL, Simoneau JA, Gilders RM, et al. Cardiorespiratory and metabolic adaptations to hyperoxic training. Eur J Appl Physiol Occup Physiol. 1996;73:38-48.

5. Vanhatalo A, Fulford J, DiMenna FJ, et al. Influence of hyperoxia on muscle metabolic responses and the power-duration relationship during severeintensity exercise in humans: a 31P magnetic resonance spectroscopy study. Exp Physiol. 2010;95:528-40.

6. Wilber RL, Holm PL, Morris DM, et al. Effect of $F(I) O(2)$ on physiological responses and cycling performance at moderate altitude. Med Sci Sports Exerc. 2003;35:1153-9.

7. Ekblom B, Huot R, Stein EM, et al. Effect of changes in arterial oxygen content on circulation and physical performance. J Appl Physiol. 1975:39:71-5.

8. Perry CG, Talanian JL, Heigenhauser GJ, et al. The effects of training in hyperoxia vs. normoxia on skeletal muscle enzyme activities and exercise performance. J Appl Physiol. 2007;102:1022-7.

9. Plat J, Pedersen PK, Jensen FB, et al. Increased working capacity with hyperoxia in humans. Eur J Appl Physiol Occup Physiol. 1992;65:171-7.

10. Welch HG. Hyperoxia and human performance: a brief review. Med Sci Sports Exerc. 1982;14:253-62.

11. Maeda T, Yasukouchi A. Blood lactate disappearance during breathing hyperoxic gas after exercise in two different physical fitness groups-on the workload fixed at $130 \%$ AT. Appl Human Sci. 1998;17:33-40.

12. Emtner M, Porszasz J, Burns M, et al. Benefits of supplemental oxygen in exercise training in nonhypoxemic chronic obstructive pulmonary disease patients. Am J Respir Crit Care Med. 2003;168:1034-42.

13. Palange $P, C$ rimi $E$, Pellegrino $R$, et al. Supplemental oxygen and heliox: 'new' tools for exercise training in chronic obstructive pulmonary disease. Curr Opin Pulm Med. 2005;11:145-8.

14. van Helvoort HA, Heijdra YF, Heunks LM, et al. Supplemental oxygen prevents exercise-induced oxidative stress in muscle-wasted patients with chronic obstructive pulmonary disease. Am J Respir Crit Care Med. 2006;173:1122-9.

15. Chance WW, Rhee C, Yilmaz C, et al. Diminished alveolar microvascular reserves in type 2 diabetes reflect systemic microangiopathy. Diabetes Care. 2008:31:1596-601.

16. Hsia CC, Raskin P. Lung function changes related to diabetes mellitus. Diabetes Technol Ther. 2007;9:73-82

17. Klein OL, Krishnan JA, Glick S, et al. Systematic review of the association between lung function and Type 2 diabetes mellitus. Diabet Med. 2010;27:977-87.
18. Sandler M. Is the lung a 'target organ' in diabetes mellitus? Arch Intern Med. 1990;150:1385-8.

19. Klein $O L$, Smith $L$, Tipping $M$, et al. Reduced diffusion lung capacity in patients with type 2 diabetes mellitus predicts hospitalization for pneumonia. Diabetes Res Clin Pract. 2011;92:12-5.

20. Ozşahin K, Tuğrul A, Mert S, et al. Evaluation of pulmonary alveolo-capillary permeability in Type 2 diabetes mellitus: using technetium 99mTcDTPA aerosol scintigraphy and carbon monoxide diffusion capacity. J Diabetes Complications. 2006;20:205-9.

21. Saler T, Cakmak G, Saglam ZA, et al. The assessment of pulmonary diffusing capacity in diabetes mellitus with regard to microalbuminuria. Intern Med. 2009:48:1939-43.

22. Cooper BG, Taylor R, Alberti KG, et al. Lung function in patients with diabetes mellitus. Respir Med. 1990;84:235-9.

23. Grataloup $\mathrm{O}$, Prieur F, Busso T, et al. Effect of hyperoxia on maximal $\mathrm{O}_{2}$ uptake in exercise-induced arterial hypoxaemic subjects. Eur J Appl Physiol. 2005;94:641-5.

24. Izdebska E, Izdebski J, Trzebski A. Hemodynamic responses to brief hyperoxia in healthy and in mild hypertensive human subjects in rest and during dynamic exercise. J Physiol Pharmacol. 1996;47:243-56.

25. Karlsen T, Hoff J, Støylen A, et al. Aerobic interval training improves $\mathrm{VO}_{2}$ peak in coronary artery disease patients; no additional effect from hyperoxia. Scand Cardiovasc J. 2008;42:303-9.

26. Stray-Gundersen J, Chapman RF, Levine BD. "Living high-training low" altitude training improves sea level performance in male and female elite runners. J Appl Physiol. 2001;91:1113-20.

27. Baron B, Dekerle J, Robin S, et al. Maximal lactate steady state does not correspond to a complete physiological steady state. Int J Sports Med. 2003;24:582-7.

28. Macsween $\mathrm{A}$. The reliability and validity of the Astrand nomogram and linear extrapolation for deriving $\mathrm{VO}_{2}$ max from submaximal exercise data. J Sports Med Phys Fitness. 2001;41:312-7.

29. Borg G, Linderholm H. Exercise performance and perceived exertion in patients with coronary insufficiency, arterial hypertension and vasoregulatory asthenia. Acta Med Scand. 1970;187:17-26.

30. Fairbarn MS, Blackie SP, McElvaney NG, et al. Prediction of HR and oxygen uptake during incremental and maximal exercise in healthy adults. Chest. 1994; 105:1365-9.

31. Tanaka H, Monahan KD, Seals DR. Age-predicted maximal HR revisited. J Am Coll Cardiol. 2001:37:153-6.

32. Mourtzakis M, González-Alonso J, Graham TE, et al. Hemodynamics and $\mathrm{O}_{2}$ uptake during maximal knee extensor exercise in untrained and trained human quadriceps muscle: effects of hyperoxia. J Appl Physiol. 2004;97:1796-802.

33. Pedersen PK, Kiens B, Saltin B. Hyperoxia does not increase peak muscle oxygen uptake in small muscle group exercise. Acta Physiol Scand. 1999;166:309-18

34. Stellingwerff T, Leblanc PJ, Hollidge MG, et al. Hyperoxia decreases muscle glycogenolysis, lactate production, and lactate efflux during steady-state exercise. Am J Physiol Endocrinol Metab. 2006:290:1180-90.

35. Brun JF, Bordenave S, Mercier J, et al. Cost-sparing effect of twice-weekly targeted endurance training in type 2 diabetics: a one-year controlled randomized trial. Diabetes Metab. 2008;34:258-65.

36. Hordern MD, Cooney LM, Beller EM, et al. Determinants of changes in blood glucose response to short-term exercise training in patients with Type 2 diabetes. Clin Sci (Lond). 2008;115:273-81.

37. Leite SA, Monk AM, Upham PA, et al. Low cardiorespiratory fitness in people at risk for type 2 diabetes: early marker for insulin resistance. Diabetol Metab Syndr. 2009;1:8.

38. Lindegaard B, Hansen T, Hvid T, et al. The effect of strength and endurance training on insulin sensitivity and fat distribution in human immunodeficiency virus-infected patients with lipodystrophy. J Clin Endocrinol Metab. 2008;93:3860-9.

39. Balducci S, Leonetti F, Di Mario U, et al. Is a long-term aerobic plus resistance training program feasible for and effective on metabolic profiles in type 2 diabetic patients? Diabetes Care. 2004;27:841-2.

40. Dunstan DW, Vulikh E, Owen N, et al. Community center-based resistance training for the maintenance of glycemic control in adults with type 2 diabetes. Diabetes Care. 2006;29:2586-91. 
41. Kirk A, Mutrie N, Maclntyre P, et al. Effects of a 12-month physical activity counselling intervention on glycaemic control and on the status of cardiovascular risk factors in people with Type 2 diabetes. Diabetologia. 2004:47:821-32.

42. Praet SF, van Rooij ES, Wijtvliet A, et al. Brisk walking compared with an individualised medical fitness programme for patients with type 2 diabetes: a randomised controlled trial. Diabetologia. 2008;51:736-46.

43. Schneider SH, Khachadurian AK, Amorosa LF, et al. Ten-year experience with an exercise-based outpatient life-style modification program in the treatment of diabetes mellitus. Diabetes Care. 1992;15:1800-10.

44. Shinji S, Shigeru M, Ryusei U, et al. Adherence to a home-based exercise program and incidence of cardiovascular disease in type 2 diabetes patients. Int J Sports Med. 2007;28:877-9.

45. Byrnes WC, Mihevic PM, Freedson PS, et al. Submaximal exercise quantified as percent of normoxic and hyperoxic maximum oxygen uptakes. Med Sci Sports Exerc. 1984;16:572-7.

46. Graham TE, Wilson BA. Effects of hypercapnia and hyperoxia on metabolism during exercise. Med Sci Sports Exerc. 1983;15:514-9.
47. Rousseau A, Bak Z, Janerot-Sjöberg B, et al. Acute hyperoxaemia-induced effects on regional blood flow, oxygen consumption and central circulation in man. Acta Physiol Scand. 2005;183:231-40.

48. Jansson PA. Endothelial dysfunction in insulin resistance and type 2 diabetes. J Intern Med. 2007;262:173-83.

49. Tabit CE, Chung WB, Hamburg NM, et al. Endothelial dysfunction in diabetes mellitus: molecular mechanisms and clinical implications. Rev Endocr Metab Disord. 2010;11:61-74.

50. Crecelius AR, Kirby BS, Dinenno FA. Intravascular ATP and the regulation of blood flow and oxygen delivery in humans. Exerc Sport Sci Rev. 2015;43(1):5-13.

51. Limberg JK, Kellawan JM, Harrell JW, Johansson RE, Eldridge MW, Proctor LT, Sebranek JJ, Schrage WG. Exercise-mediated vasodilation in human obesity and metabolic syndrome: effect of acute ascorbic acid infusion. Am J Physiol Heart Circ Physiol. 2014;307(6):H840-7.

\section{Submit your next manuscript to BioMed Central and we will help you at every step:}

- We accept pre-submission inquiries

- Our selector tool helps you to find the most relevant journal

- We provide round the clock customer support

- Convenient online submission

- Thorough peer review

- Inclusion in PubMed and all major indexing services

- Maximum visibility for your research

Submit your manuscript at www.biomedcentral.com/submit

() Biomed Central 